\title{
Variations in home care programs across Canada demonstrate need for national standards and pan-Canadian program
}

I $\mathrm{t}$ has become a truism that home care is a critical component of the future health care system, as skyrocketing costs persuade governments to seek answers in community settings on the premise that there's a "bigger bang for the buck" to be had, while more and more patients seek care in familiar and comfortable settings.

Yet critics bemoan tremendous policy neglect in the whole area of home care, arguing that it has led to a patchwork of programs across the nation, with access and availability conditional on geographic region, if not chance. Others contend that major efficiencies and health benefits that would accrue from improved home care programming underscore the need for national standards and readier access to home care, if not a panCanadian program.

"This country is incredibly inconsistent. When it comes to using home care, it can be a crapshoot as to where you live and what services are available," says Doug Angus, a health economist and professor at the University of Ottawa's Telfer School of Management.

The checkerboard home care situation is, of course, a function of fractured jurisdiction over health care in Canada. Home care is not an insured service under the Canada Health Act and thus falls to the whim of provinces and territories. While they have all implemented some measure of home care services, there are significant variations in access, costs and wait times.

"In the North, we know a child may wait up to a year for basic occupational or physical therapy services and up to 2 years for speech language solutions," says Pamela Fralick, president and chief executive officer of the Canadian Healthcare Association, which this spring issued a policy brief, Home Care in Canada: From the Margins to the Mainstream, sketching those enormous variations in service.

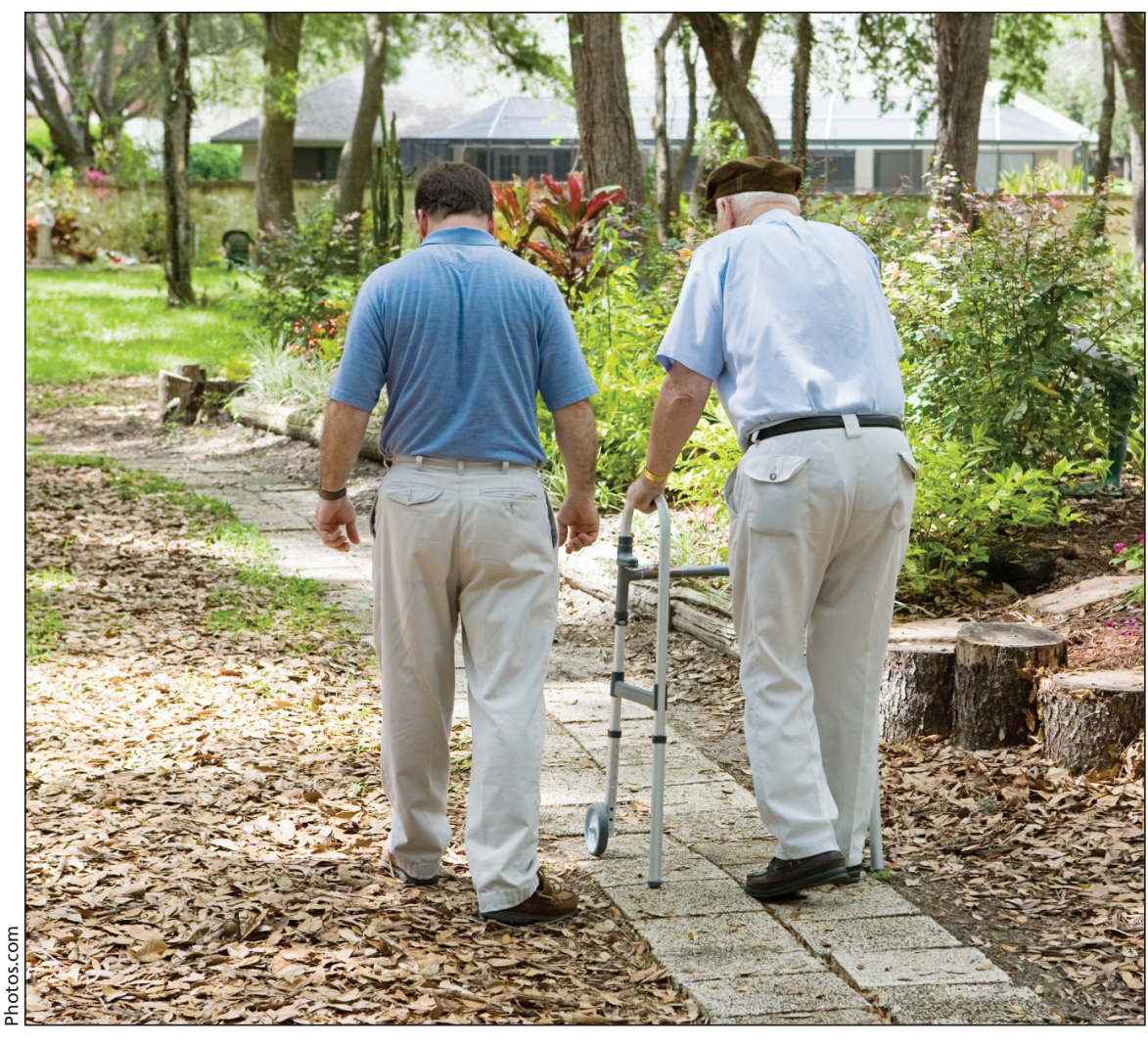

The Canada Institute for Health Information says that government spending on home care grew to $\$ 3.4$ billion in $2003 / 04$, representing an average annual growth rate of $9.2 \%$ over the course of a decade.

Efforts to achieve at least a measure of consistency across the nation have largely been confined to a single intergovernmental agreement, the 10-Year Plan to Strengthen Health Care, which was struck in 2004. Under that agreement, federal, provincial and territorial governments committed to give firstdollar coverage for acute home care for a 2-week period; community mental health home care for a 2 -week period and palliative care.

"The accord is something but it's very minimalist," says Fralick. "Because we're looking for comparable access to services, we'd like to see the federal government take a leadership role to provide guiding principles about what the best home care practices are and how funding should unfold across the country."

There's also significant variation in the method of delivering home care. In its brief, the Canadian Healthcare Association indicates that 4 basic models of service delivery have evolved across the country.

Saskatchewan, Manitoba, Nunavut, the Northwest Territories, Quebec, Prince Edward Island and Yukon have a public provider model, in which government employees directly manage and deliver home care, including professional services such as nursing, and home support services, including personal support, housework, meals, shopping and respite care. Intermediate agencies either play a limited role or have no role at all. 
In the second model, adopted by British Columbia, New Brunswick and Newfoundland, all professional services are delivered by public employees. Home support services are delivered by private agencies.

Both public and private employees provide professional home care services in the third model. In Alberta and Nova Scotia, public employees provide the administration and home support services are contracted out.

In Ontario, all publicly paid professional home care and support services are contracted out to the private sector. Community Care Access Centre employees provide coordinating services and a few centres deliver services through their employees.

What also emerges from the brief is that there is tremendous demand for home care; that home care programming is inextricably linked to other social support programming; and that home care programs are now largely confined to short-term health problems.

Home care largely serves seniors, people with developmental disabilities, people with mental illnesses or chronic conditions, and children with special needs. In 2003, Statistics Canada reported that $5 \%$ of Canadians over 18 an estimated 1.2 million - received some form of home care in the prior year. Over 500000 were seniors. Twothirds of patients who accessed government-subsidized home care in 2003 were women.

The Canadian Healthcare Association says significant gaps in the home care coverage exist, especially in relation to children with special needs, First Nations and Inuit people, those who require long-term home care, people who are dying and people with mental illnesses.

The demand, as well as the need for both medical and social support under home care programming, leads Evelyn Shapiro, who has been called the "mother" of Manitoba's home care system, to believe that home care is a crucible for Canada's health care system. "Home care is a unique program because it really doesn't only consist of medical services, it consists primarily of social supports," says Shapiro, a

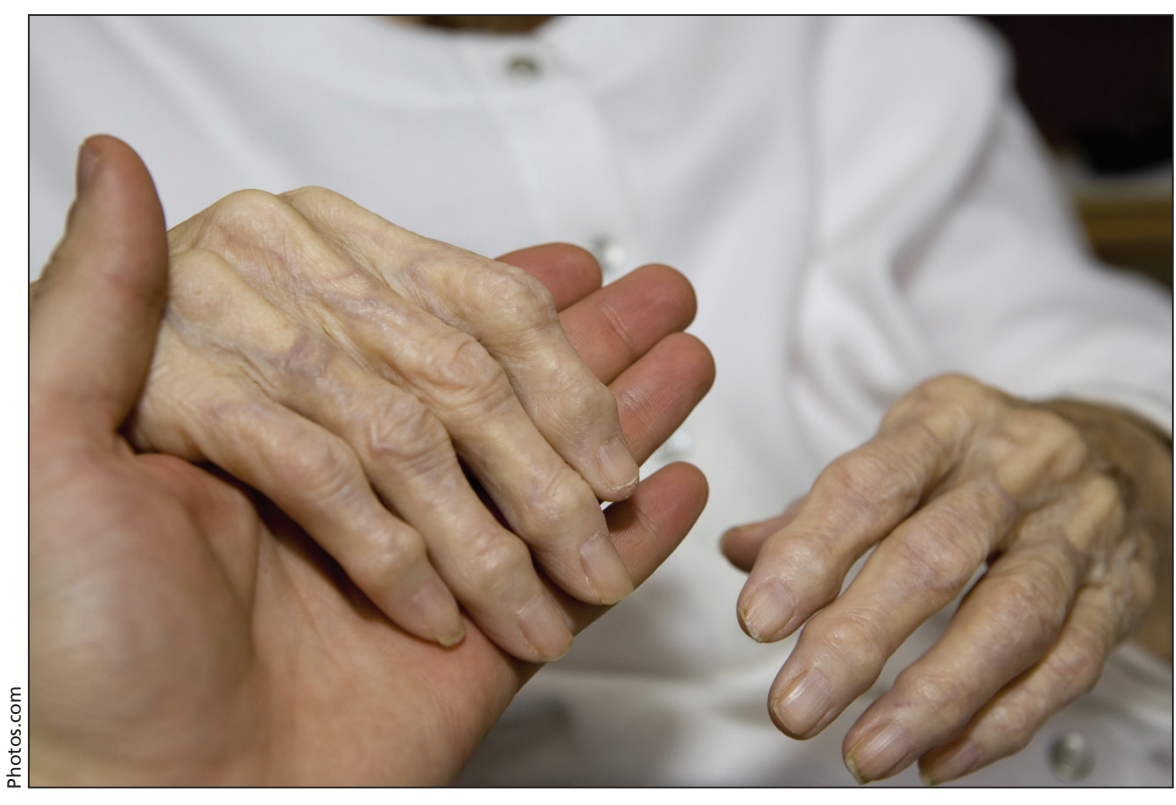

The Canadian Healthcare Association estimates that 1 in 4 Canadians took care of a friend or family member with a serious health problem in 2007.

senior scholar at the University of Manitoba's Department of Community Health Sciences.

Others, like Marcus Hollander, president of Hollander Analytical Services, a research, informatics and communications advisory firm, say that the nature of the demand points to the need to ensure that lengthier time lines for home care are built into the system. "People with ongoing, long-term care needs should be put back into the policy mix nationally."

Hollander also says the nationwide disparities in services offered, fees and coverage of drugs, supplies and equipment are extremely problematic for families who are forced to relocate. "There are issues around - if you move to a new province - how long it takes you to be eligible for services in a new location."

The variations can lead to medical migration, says Fralick, recalling a July 2008 case in which a family moved from Halifax, Nova Scotia, to Winnipeg, Manitoba, to access services for their autistic child. "We have the Canada Health Act for a reason, and one of its basic tenets is universal access to basic services. All Canadians should have access to a comparable basket of services no matter where they live."

\section{Family caregivers}

Beyond that lies the question of providing greater financial support for volunteer or family caregivers. The Canadian Healthcare Association brief states that 1 in 4 Canadians took care of a friend or family member with a serious health problem in 2007. Hollander and Neena Chappell, Canada Research Chair in Social Gerontology at the University of Victoria in Victoria, British Columbia, estimate that the contributions of unpaid caregivers in 2009 will be $\$ 25$ billion (Healthc Q. 2009; 12[2]: 42-9).

The Canadian Healthcare Association says that those many disparities and variables indicate that federal legislation to deal with home care on a panCanadian basis is "much needed." The association also advocates far greater use of information and communications technology, including electronic patient records and telehealth.

Canada's largest nonprofit provider of home and community care concurs on the need for a national approach. "Increasing public investment, looking at the health human resource issue and recognizing that workers in home and community sector have a right to the same compensation to those working in acute care system need to be on the agenda," says Diane McLeod, executive vice-president of the Victorian Order of Nurses. 
A national program would also benefit volunteer caregivers, says Dr. Denise Alcock, former dean of the faculty of health sciences at the University of Ottawa. "We need to invest much more in caregiver support. If we had national agreement on home care service standards and the ability to allocate appropriate resources, there would be far less pressure on informal caregivers."

But others, like the Shirlee Sharkey, the chief executive officer of Saint Elizabeth Healthcare, a nonprofit charitable organization that provides home care services in Ontario and $\mathrm{BC}$, as well as First Nations support in BC, Saskatchewan and Manitoba, argue that a pan-Canadian approach is unnecessary.

"The drivers of what people need for health care and service in different locations, in particular in their homes, may be very different. If we're so concerned with consistency and ensuring a blanket of care and an approach that is very standardized, it might not accommodate the diversity of needs that exist."

Internationally, though, several countries have found there is a tremendous benefit to a national approach, Fralick says, pointing to Australia's 20-year-old home care system, which eliminated state-by-state variations in the quantity and scope of home care services.

Australia has been able to develop a national program with minimum standards that is delivered at the provincial level," says Janice Keefe, Canada Research Chair in Aging and
Caregiving Policy at Mount Saint Vincent University in Halifax, Nova Scotia. "Australia has also put a number of caregiver supports in place, including a national respite program and financial supports that are encompassed in a whole health package."

Other western European countries, such as Denmark, have also taken a leading role, she adds.

But Sharkey says importing models from other nations is not always easy. "Lessons learned have to be incorporated into our societal norms, our cultural expectations and our historical context - which is very different from many of these other countries." Krista Seggewiss, Ottawa, Ont.

DOI:10.1503/cmaj.090819 